\title{
Selectable Marker Gene Removal and Expression of Transgene by Inducible Promoter Containing FFDD Cis-Acting elements in Transgenic Plants
}

\author{
Shiva Hamzeh, Mostafa Motallebi *, Mohammad Reza Zamani *, Zahra Moghaddassi Jahromi \\ Department of Agricultural Biotechnology, National Institute of Genetic Engineering and Biotechnology, Tehran, Iran \\ ${ }^{*}$ Corresponding authors: Mohammad Reza Zamani; Mostafa Motallebi, National Institute of Genetic Engineering and Biotechnology, Tehran, Iran. Tel: +98- \\ 2144787363, Fax: +98-2144787363, E-mail: zamani@nigeb.ac.ir; motalebi@nigeb.ac.ir
}

Received: December 08, 2014; Revised: June 15, 2015; Accepted: August 18, 2015

Background: Selectable marker gene (SMG) systems are critical for generation of transgenic crops. Transgenic crop production without using SMG is not economically feasible. However, SMGs are non-essential once an intact transgenic plant has been established. Elimination of SMGs from transgenic crops both increases public acceptance of GM crops and prepares gene stacking possibility for improvement of complex traits. Synthetic inducible promoters provide an efficient and flexible strategy to regulate transgene expression.

Objectives: This study aimed to construct a transformation vector based on Cre/loxP recombination system to enhance efficiency of SMG-free transgenic plant production followed by post-excision expression of gene of interest in transgenic plants by a pathogen inducible promoter.

Materials and Methods: In pG-IPFFDD-cre ${ }^{\text {int }}$-gus int construct, cre recombinase and selectable marker gene (nptII) cassettes were placed between the two loxP recognition sites in direct orientation. Seed-specific Napin promoter was used for regulation of Cre expression in transgenic seeds. In the construct, loxP flanked sequence containing $n p t I I$ and recombinase cassettes, located between a pathogen inducible promoter containing FFDD cis-acting elements and $\beta$-glucuronidase coding region. The cunstuct was transformed into Nicotiana tabaccum via Agrobacterium-mediated transformation.

Results: The results showed that both cre and nptII excision occurs in T1 progeny tobacco plants through seed-specific cre expression. The excisions were confirmed by methods activation of the gus gene, germination test on kanamycin-containing medium and molecular analysis. Inducibility of gus expression by FFDD-containing promoter in T1 leaf tissues was confirmed by histochemical Gus staining assay.

Conclusions: The established system is not only an efficient tool for marker gene elimination but also provides possibility for inducible expression of the transgene.

Keywords:Cis-acting elements; Inducible promoter; Selectable marker gene; Self-excision system

\section{Background}

Transformation technologies have limitations for introduction of multiple genes into plant genomes. One of these limitations is remaining of selectable marker genes in transgenic plants that limit reusing of these genes in sequential transformations (1). Remaining of selectable marker genes $\left(\mathrm{SMG}_{\mathrm{S}}\right)$, usually an antibiotic- or herbicide-resistant gene (2), in plant genomes has raised concerns from both regulatory agencies and the public. Horizontal transfer of antibiotic resistance genes from plants to other microorganisms, medically related bacteria or intestinal microorganisms are distinguished as major biosafety concerns (3).

Varieties of methodologies have been developed to obtain SMG-free transgenic plants. Transfer of the trait gene and SMG via co-transformation and the subsequent segregation in the progeny was one of the earliest methods developed for marker gene elimination $(4,5)$. Homologous recombination system $(6,7)$, use of transposable elements (8), and site-specific recombination $(9,10,7)$ are the other strategies. The cotransformation and use of transposons are rather time consuming and labor intensive. These techniques require further complementary steps such as selection of SMG free individuals in subsequent segregating generations. Occurrence of unwanted deletions due to uncontrolled recombination events makes the homologous recombination system less attractive (11).

Site-specific recombination based strategies are desirable for SMGs elimination. In these systems, 
recombination reactions catalyzed by recombinase proteins, excise any DNA sequence that is flanked between two directed recombinase recognition sites in the same orientation. The well-known Cre/loxP system from bacteriophage P1 has been widely used in plant biotechnology (6). Retransformation (12), sexual crossing $(13,14,15)$ and self-excision strategy $(16$, 17) are the three successful strategies for delivery of cre recombinase in transgenics. In the first two strategies much time is needed to produce marker-free transgenic plants. Additionally, it has been reported that constitutive expression of cre gene in some plants result in growth retardation and a distinct pattern of chlorosis in leaves (18).

In self-excision strategy, recombinase gene is located on the same T-DNA together with selectable marker gene between the recombination sites and Cre gene expression can be limited by using chemical (19, $20,17,21)$ or heat-shock regulated promoters $(16,22$, 23). Using inducible promoters have limitations such as: an additional step to activate the recombinase, an extra regeneration step and probable side-effects of inducers on plant proliferation. Conditional expression of Cre recombinase using tissue-specific promoters seems to be the method of choice nowadays. Self-excision systems using pollen (24), floral (25), germ-line (26) and seed-specific promoters (27) have been reported for the elimination of SMGs.

\section{Objectives}

A genetic system based on Cre/loxP recombination system was constructed for co-elimination of SMG and recombinase. Following the excision, a pathogen-elicitor inducible promoter drives the gene of interest. This system was developed to remove the marker gene in the T1 progeny of transgenic plants in a single round of transformation. The strategy relies on a seed-specific promoter to control the expression of the recombinase to produce SMG-free transgenic plants. Feasibility of this genetic system was evaluated in Nicotiana tabacum to obtain complete SMG-free and salicylic acid -inducible transgenes.

\section{Materials and Methods}

\subsection{Materials}

Restriction enzymes, T4 DNA ligase, Taq DNA polymerase and PCR buffers purchased from Fermentas (USA). Plant growth hormones including BAP, NAA and histochemical Gus activity assay buffers $\left(\mathrm{NaH}_{2} \mathrm{PO}_{4}\right.$, Triton X-100, $\mathrm{Na}_{2}$ EDTA, 5-bromo4-chloro-3-indolyl glucuronide) was purchased from sigma (USA). Kanamycin, cefotaxime, Salicylic acid prepared from Merck (Germany). E. coli, DH5 $\alpha$ and Agrobacterium tumefaciens, LBA4404 strain used for cloning and plant transformation. Nicotiana tabacum cv. Samsun was used as plant material for transformation.pegGOLD plant DNA Mini Kit (PeQlab, Germany) was used for DNA extraction. pTZ 57R/T vector was purchased from Fermentase (USA).

\subsection{Construction of Self-Excision System}

The self-excision vector was constructed using classical cloning techniques according to Sambrook et al. (28). 2100 bp gus gene ORF with additional KpnI and SmaI recognition sites amplified using ks-gusF and sac-gusR primers (Table 1). The purified amplicon was inserted into the digested pGPV-gusint plasmid (Figure 1A) (29) with XhoI. The resulting construct was named as pG-KSgusint. The synthetic IP-FFDD fragment containing: IPFFDD pathogen inducible promoter, 34 bp loxP recognition site (ATAACTTCGTATAATGTATGCTATACGAAGTTAT) and nos terminator, were inserted as a DraIII fragment into the DraIII cleaved pG-KSgusint vector. NosT sequence was added between inducible promoter and $n p t \mathrm{II}$ cassette to prevent from probable effect of inducible promoter on $n p t \mathrm{II}$ gene expression. The resulting construct was

Table 1. Oligonucleotide primers used for transgenes

\begin{tabular}{lc}
\hline Oligonucleotide name & Sequence \\
\hline ks-gusF & 5'-CTCGAGGGTACCCGGGACCATGGTAGATCTGAGGGT AA-3' \\
sac-gusR & 5'-ATTCGAGCTCGGTAGCAATTC-3' \\
creF & 5'-CTCGAGATGTCCAATTTACTGACCGTA-3' \\
creR & 5'-CTCGAGATA ACTTC GTATAATG TATGCTATACGAAGTTATC CCCCCTAT TTCTCAGGCACA-3' \\
nptIIF & 5'-CATACCGTTCCCGAGTAA GGATG-3' \\
nptIIR & 5'-TCGAGTGGTGATTTTGTGC-3' \\
F1 & 5'-GACTAGTTTGTCAATGTCATTAAATT-3' \\
gusR & 5'-CCGGCATAGTTAAAGAAATCAT G-3' \\
\hline
\end{tabular}




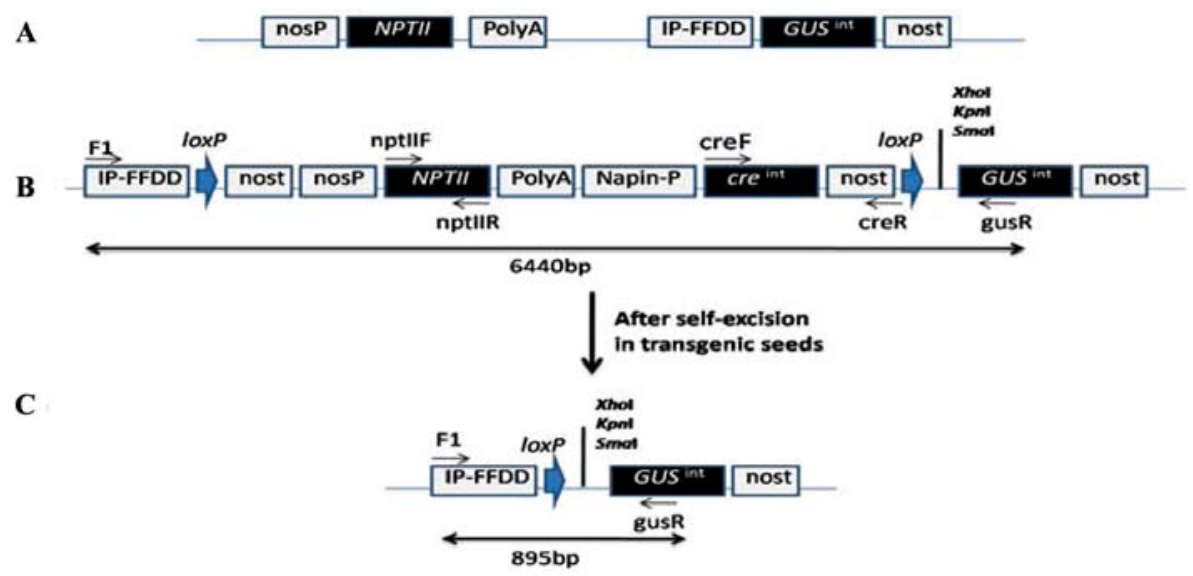

Figure 1. A: The schematic diagrams of the pGPTV-gus int construct, B: the Cre/loxP self-excision system used for marker gene excision in tobacco $\mathrm{C}$ : the predicted Cre/loxP self-excision after recombination in transgenic seeds. IP-FFDD: pathogen inducible promoter; NPTII: neomycin phosphotransferase II gene; nosT: nos terminator; nosP: nos promoter; napinP: seed specific promoter; Creint, the bacteriophage P1 Cre recombination gene; GUS int: the $\beta$-glucuronidase complete coding region

referred to as pG-IPFFDD-gusint. Napin promoter sequence inserted as a HindIII/XhoI fragment into digested pG-IPFFDD-gusint vector with the same enzymes to drive $C r e$ gene. The new construct was named as pG-IPFFDD- napinP-gus int. $C r e^{\text {int }}$ ORF with the nos terminator was amplified using creF and creR primers (Table 1), (with 34 bp loxP sequence in $5^{\prime}$ end of reverse primer) from pLH-cre-gus plasmid (30). The amplicon was inserted as a XhoI-restricted fragment into XhoI cheaved pG-IPFFDD- napinP-gus ${ }^{\text {int }}$ vector. The final construct was designated as $\mathrm{pG}-$ IPFFDD-gus ${ }^{\text {int }}$-creint $($ Figure 1B).

\subsection{Genetic Transformation and Molecular} Confirmation of Transgenic Plants

The self-excision plasmid pG-IPFFDD-gusint_ cre $^{\text {int }}$ was transferred into the Agrobacterium tumefaciens strain LBA4404 via heat shock. Tobacco transformation was performed by $A$. tumefaciens LBA4404 (pG-IPFFDD-gusint-creint) according to Horsch et al. (31). Briefly, tobacco leaf discs were used as explants. After 1-day pre-culture, Agrobacterium inoculation, and 3-day co-cultivation on COM medium (MS medium supplemented with $0.2 \mathrm{mg} . \mathrm{L}^{-1} \mathrm{NAA}$ and $2 \mathrm{mg} . \mathrm{L}^{-1}$ $\mathrm{BAP}$ ), infected leaf discs were placed on RM medium (MS medium containing $0.2 \mathrm{mg} . \mathrm{L}^{-1}$ NAA, $2 \mathrm{mg} . \mathrm{L}^{-1}$ BAP, $100 \mathrm{mg} . \mathrm{L}^{-1}$ kanamycin, and $200 \mathrm{mg} . \mathrm{L}^{-1}$ cefotaxime) for 8 weeks. Adventitious shoots were excised and transferred to a kanamycin-free MS medium. The rooted shoots were transplanted to soil for growth and self-pollination. Genomic DNA was prepared from leaf of plants using peqGOLD Plant DNA Mini Kit
(PeQlab). The presence of T-DNA in primary transgenic plants genome was confirmed by PCR. The presence of nptII and cre genes was detected by PCR amplification using two primer sets, nptIIF, and nptIIR for amplification of $950 \mathrm{bp} n p t \mathrm{II}$ fragment and creF and creR for amplification of $2000 \mathrm{bp}$ cre fragment. Genomic plant DNA (50 ng) was used as template for PCR reactions. Non-transformed plant DNA was used as negative control.

\subsection{Seed Germination Test}

To determine the SMG-free phenotypes (kanamycin sensitive) in $\mathrm{T} 1$ progeny plants, a number of seeds from each primary transgenic line were sown under selective condition (100 mg.L-1 kanamycin). After 21 days, kanamycin resistant seedlings (normal seedlings with developed shoot and root systems) and sensitive seedlings (small seedlings with yellow or pale green cotyledons and undeveloped roots) were counted.

\subsection{Salicylic Acid Treatment and Gus Activity Analysis}

In order to investigation of excision event, histochemical Gus activity assay in kanamycin susceptible transgenic lines was performed according to Jefferson et al. (32). For histochemical analysis, at first leaf discs derived from $\mathrm{T} 1$ progeny plants were incubated in $0.2 \mathrm{mM}$ salicylic acid (as a pathogen elicitor) in vacuum for $20 \mathrm{~min}$ for induction of promoter and incubated in dark condition for 72 hours, then incubated in a reaction buffer containing 50 mmol.L-1 $\mathrm{NaH}_{2} \mathrm{PO}_{4}$ (pH 
7.0), 0.1\% Triton X-100, 10 mmol.L-1 $\mathrm{Na}_{2}$ EDTA and 1 mmol.L-1 5-bromo-4-chloro-3-indolyl glucuronide (XGluc) at $37^{\circ} \mathrm{C}$ for $16-24 \mathrm{~h}$. The samples were discolored with $70 \%$ ethanol and observed under a light microscope.

\subsection{Molecular Analysis of SMG-Free Plant}

Genomic DNA of kanamycin sensitive lines was extracted from leaf tissues of T1 progeny plants. Two sets of primers, including F1/gusR and nptIIF /nptIIR primers (Table 1) were used for analysis of Cre mediated recombination events. The reaction mixture $(25$ $\mu \mathrm{L}$ ) contained $50 \mathrm{ng}$ template DNA; $2.5 \mu \mathrm{L}$ of $10 \mathrm{x}$ PCR buffer; 10 pmol of each primer, $200 \mu \mathrm{M}$ dNTPs and $0.5 \mathrm{U}$ of Taq polymerase. For analysis of precise recombination event, an 895 bp PCR product amplified by using F1/gusR primers (Table 1) was cloned into $\mathrm{pTZ} 57 \mathrm{R} / \mathrm{T}$ vector and sequenced with M13 primers.

\section{Results}

\subsection{Generation and Identification of Transgenic Plants}

Primarily the transgenic plants were selected based on resistance to kanamycin. The cre gene expression in seeds of these transgenic lines resulted in co-elimination of cre and nptII cassettes and the loss of the kanamycin resistance in T1 progeny plants. After self-excision, the gus gene went under the control of inducible promoter IP-FFDD (Figure1 C).

After Agrobacterium-mediated transformation of
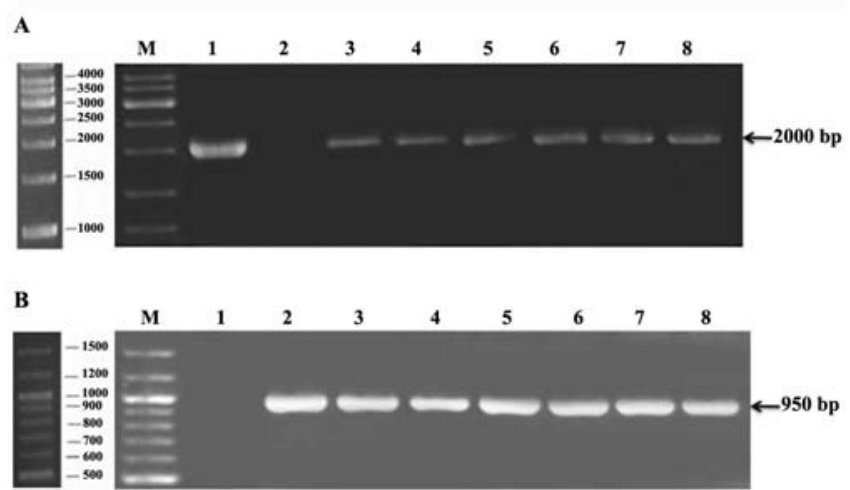

Figure 2. PCR of primary transgenic plants obtained for TDNA presence. A: PCR with creF/creR primers; M: molecular marker $1 \mathrm{~kb}$ : positive control (pG-IPFFDD-creint_gus ${ }^{\text {int }}$ plasmid); 2: negative control (wild type tobacco); 3-8: transgenic tobacco plants B: PCR results with primers nptIIF/nptIIR. M: molecular marker mix; 1: negative control (wild type tobacco); 2: positive control (pG-IPFFDDcreint_gus $^{\text {int }}$ plasmid); 3-8: transgenic tobacco plants the tobacco plants, 10 kanamycin- resistant putative transgenic lines containing pG-IPFFDD-cre ${ }^{\text {int }}$-gus ${ }^{\text {int }}$ were obtained, and analyzed for the presence of cre and $n p t$ II genes by PCR using two sets of specific primers, including creF/creR (2000 bp) and nptIIF/nptIIR (950 bp) (Figure 2).

Transgenic lines were self-pollinated to obtain T1 seeds. All transgenic lines showed healthy phenotype and no abnormality in shape or fertility was observed. Mature seed materials from these lines were used for marker gene elimination analysis.

\subsection{Seed Germination Assay for Marker Elimination}

Seeds from self-pollinated transgenic plants were used to investigate the marker-free plants. Seeds were germinated in the presence of $100 \mathrm{mg} . \mathrm{L}^{-1}$ kanamycin to distinguish the SMG-free phenotypes. The kanamycin susceptibility ratio was estimated based on the growth of $\mathrm{T} 1$ seeds on antibiotic containing medium. Susceptible and resistant germinated seeds were clearly recognized at 3 weeks after germination (Figure 3). Small seedlings with small cotyledons and undeveloped root recognized as susceptible and normal seedlings with developed shoot, green cotyledon and developed root system recognized as resistant seedlings. In kanamycin germination assay, transgenic seeds with pBI-nptII-gus plasmid were used as negative control, which showed kanamycin resistant phenotype. Wild type seeds used as positive control showing kanamycin sensitive phenotype (Figure 3). Segregation analysis demonstrated that three transgenic lines (TF1, TF5 and TF6) were kanamycin-sensitive $(100 \%)$ while other lines (TF2, TF3 and TF4) were differentiated to kanamycin sensitive and resistant phenotypes. The frequency of kanamycin susceptible plants was varied: 100 out of 137 for TF2, 61 out of 93 for TF3 and 44 from 147 for TF4 (Figure 4). Seed germination results showed that self-excision event occurred between loxP sites, and SMG-free plants were produced.

\subsection{Histochemical Staining Assay}

To confirm the results of antibiotic resistant gene elimination, T1 progeny plants of three kanamycin sensitive lines were analyzed by histochemical Gus staining assay to evaluate the functionality of inducible promoter (IP-FFDD) which is now located upstream of gus gene. The gus reporter gene would be expressed by the IP-FFDD inducible promoter after self-excision in transgenic seeds (Figure 1C). Analysis of the gus expression in $\mathrm{T}_{1}$ progeny of three 

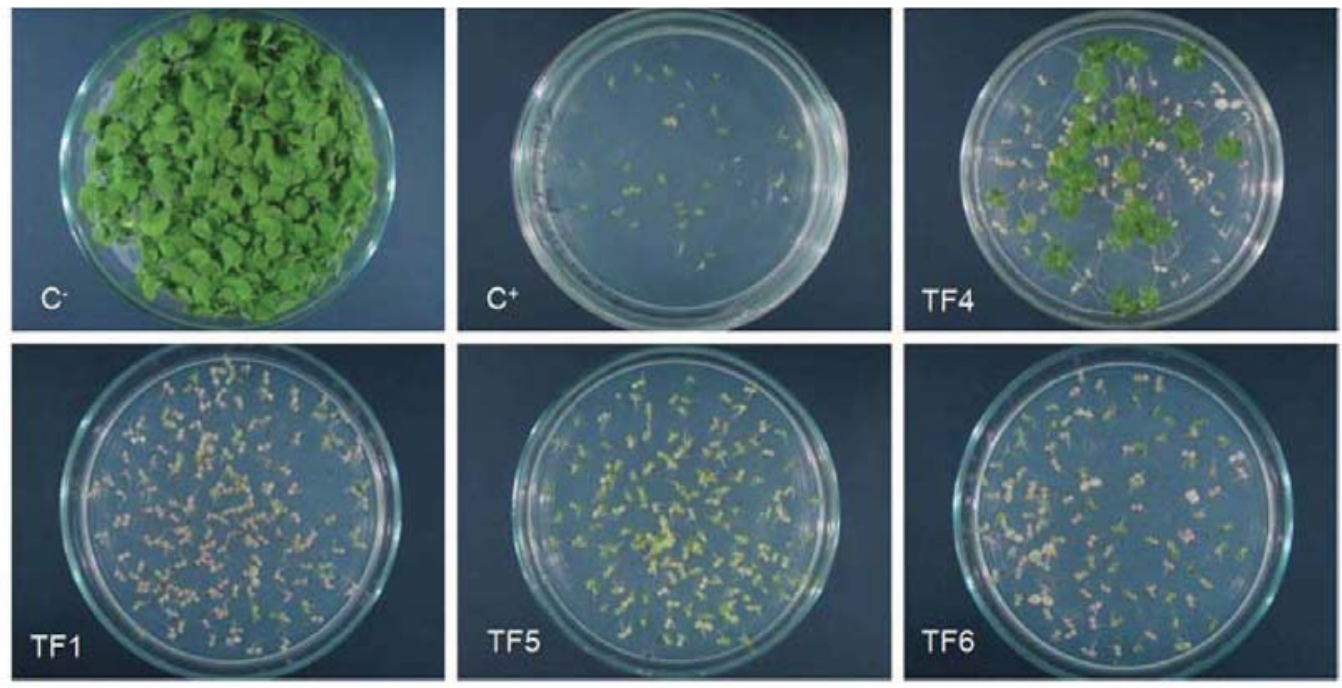

Figure 3. T1 seeds germination on kanamycin-containing medium. (C-) pBI121 harboring transgenic seeds (C+) wild type seeds (TF4, TF1, TF5 and TF6) Transgenic plants seeds. The results show that the $n p t I \mathrm{I}$ marker gene is completely removed in TF1, TF5 and TF6 progenies

kanamycin susceptible lines $\left(\mathrm{TF}_{1}, \mathrm{TF}_{5}\right.$ and $\left.\mathrm{TF}_{6}\right)$ confirmed Gus activity in leaf tissue after induction by salicylic acid as an inducer (Figure 5). Non-induced leaf discs were used as the negative control. These observations was suggestive of occurance of successful recombination event between two loxP sites in three sensitive lines. The Gus assay exhibited that the sitespecific recombination event in transgenic lines did not interfere with the IP-FFDD inducible promoter function.

\subsection{Molecular Confirmation of SMG Elimination}

To confirm the results of seed germination and Gus expression assays, molecular analysis was carried

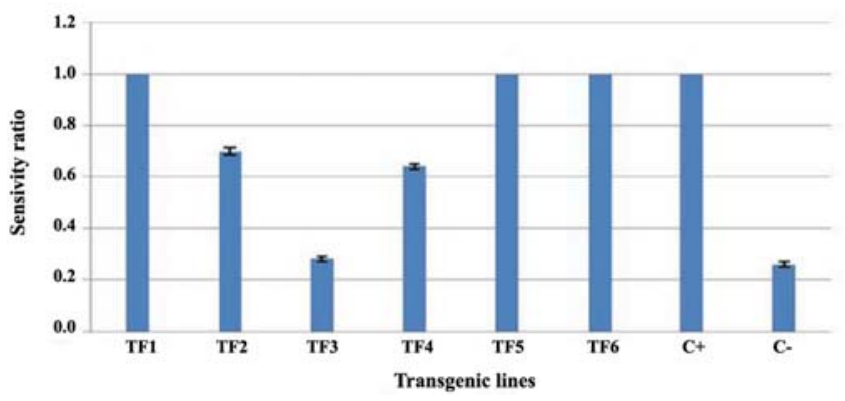

Figure 4. Phenotypic analysis of SMG excision. Sensitivity ratio was calculated by ratio of kanamycin-sensitive $\mathrm{T} 1$ progeny to all germinated $\mathrm{T} 1$ seeds in selective condition for each transgenic line. Each value represents the mean $(+$ standard error) of three independent experiments. Columns are significantly different at $\mathrm{p}<0.05$ out using $\mathrm{T}_{1}$ progenies (lines 1,5 and 6 ). By seed-specific expression of Cre, the DNA sequence between the two direct loxP sites was excised. Thus, after Cre/loxP-mediated excision, only an 895 bp DNA fragment was amplified with the primers $\mathrm{F}_{1} /$ gusR, but nptII gene was not amplified by nptIIF/nptIIR primers (Figure 1C). Based on the above principle, some T1 progeny plants for each line were investigated by PCR with primers F1/gusR and nptIIF/nptIIR,. Amplification of 895 bp fragment indicated that DNA recombination occurred in kanamycin sensitive lines (Figure 6A). Thirteen independent $\mathrm{T} 1$ progenies for each sensitive lines (TF1, TF5 and TF6) were examined for amplification of $895 \mathrm{bp}$ band using F1/gusR

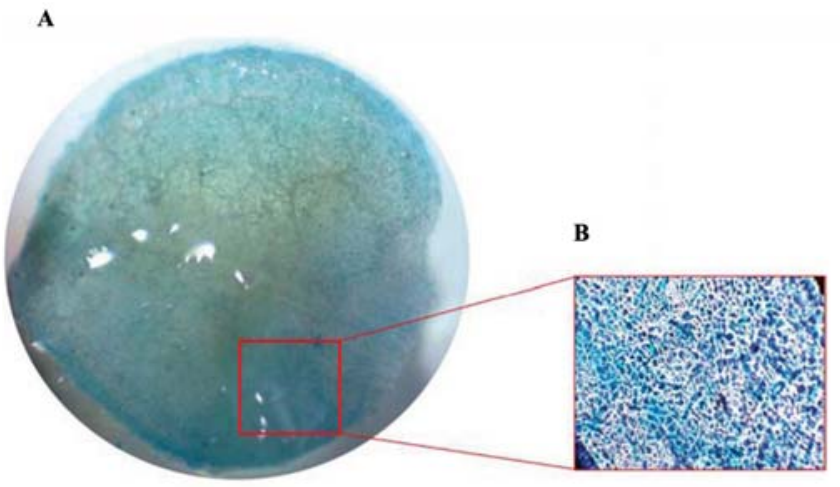

Figure 5. Gus expression analysis in leaf tissue of T1 progeny of kanamycin sensitive transgenic lines. A: histochemical staining of leaf after induction with salicylic acid B: a close-up of gus expression in leaf cells with 100x magnification by a light microscope 
primers. Out of 13 plants for each line, 10 for line-1, 8 for line- 5 and 11 for line- 6 were positive. Since F1/gusR primers were not able to amplify the $6440 \mathrm{bp}$ fragment from the complete T-DNA of the investigated $\mathrm{T} 1$ plants, the nptIIF/R primers were used for the identification of complete SMG-free events. Amplification of $950 \mathrm{bp}$ fragment using nptIIF/R primers indicated incomplete excision. Genomic DNAs isolated from T1 progeny that only produced 895 bp amplicon were considered to be completely marker-free. Thus, others with more than one band with the right size such as plants producing bands of $895 \mathrm{bp}$ and $950 \mathrm{bp}$ PCR products were not followed the excision event properly. PCR analysis data for nptII gene removal was shown in (Table 2).

To further validate the DNA excision in T1 progeny plants, the $895 \mathrm{bp}$ PCR products from SMG-free plants were cloned into $\mathrm{pTZ} 57 \mathrm{R} / \mathrm{T}$ cloning vector and sequenced. The DNA fragment between the two loxP sites was removed precisely and only one $\operatorname{lox} P$ site remained between IP-FFDD inducible promoter sequence and gus open reading frame (Figure 6B). The flanking regions outside of the two loxP sites remained intact. This fragment also contained the intact recognition sites of KpnI, SmaI and XhoI enzymes.

\section{Discussion}

In the present study, the pG-IPFFDD-cre ${ }^{\text {int }}$-gus ${ }^{\text {int }}$ self-excision vector was introduced as an efficient genetically system for nptII gene elimination and inducible expression of interest gene by FFDD cis-acting containing promoter. This system was designed on the basis of Cre/loxP site-specific recombination system. Cre/loxP is highly efficient system for transgene excision (6). To accomplish this efficient marker gene self-excision system, we constructed a self-excision system in which the cre gene was regulated by Napin as a seed-specific promoter. Napin promoter is functional in embryo and endosperm of developing canola seeds (33). The functional analysis of this seed-specific promoter in tobacco indicated that the napin promoter is inactive in vegetative tissues (34). Other studies using various tissue-specific promoter in cre/lox $P$ selfexcision system exhibited that these promoters are regulated in expected tissue $(35,36,37)$.

To investigate the functionality of designed selfexcision system, the kanamycin germination test was carried out for $\mathrm{T} 1$ progeny plants. The results showed that kanamycin sensitive phenotype was detected in all transgenic lines indicating that site-specific recombination event occurred in these lines. The elimination of nptII and recombinase cassettes in three kanamycine sensitive lines was subsequently verified by amplification of 895 bp recombined fragment (Figure 6A) and the sequence of PCR product (Figure 6B). The complete $n p t I I$ excision efficiency varied between $72.7 \%$ and $100 \%$ for the three kanamycin sensitive lines. It can be speculated that variation in the complete SMG-

$\mathbf{A}$

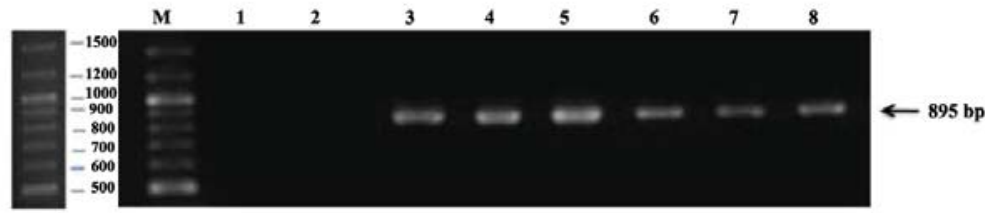

B
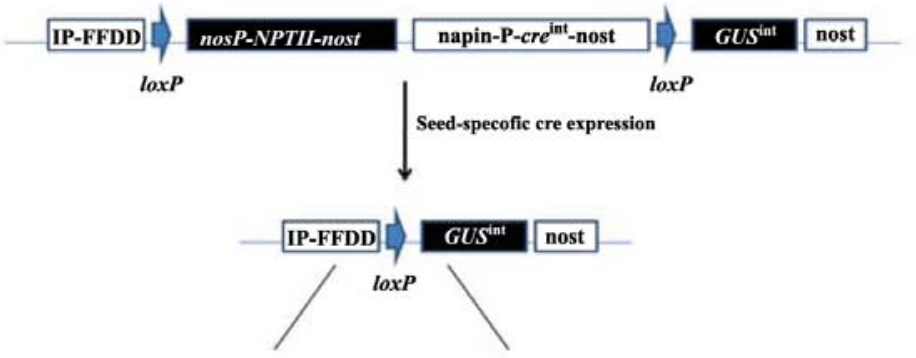

CATTIGGAGAGGACACGATAACTTCGTATAGCATACATTATACGAAGTTAT CTCGAGGGTACCCGGGTGGCCACCATGGTA Xhol $\overline{\text { KpnI } \overline{S m a I}}$

Figure 6. Molecular analysis of SMG-free plants. A: PCR results for kanamycin- sensitive T1 progeny plants with F1/gusR primers; M: Molecular marker; 1: negative control (wild type plant); 2: negative control (pG-IPFFDD-cre ${ }^{\text {int }}$-gus ${ }^{\text {int }}$ plasmid); 3-8: T1 progeny of transgenic lines (1, 5 and 6 lines). Amplification of 895 bp fragment confirmed SMG excision. B: Sequence analysis of post-recombination $895 \mathrm{bp}$ fragment. The $34 \mathrm{bp}$ sequence of loxP site and restriction enzymes recognition sites are underlined 
Table 2. PCR analysis data for SMG removal

\begin{tabular}{lcccc}
\hline $\begin{array}{l}\text { Line } \\
\text { number }\end{array}$ & $\begin{array}{c}\text { Total number } \\
\text { of samples }\end{array}$ & $\begin{array}{c}\text { Excision } \\
\text { positive }\end{array}$ & $\begin{array}{c}\text { Nptll neg- } \\
\text { ative }\end{array}$ & $\begin{array}{c}\text { complete exci- } \\
\text { sion efficiency }\end{array}$ \\
\hline 1 & 13 & 10 & 10 & $100 \%$ \\
5 & 13 & 8 & 7 & $87.5 \%$ \\
6 & 13 & 11 & 8 & $72.7 \%$ \\
\hline
\end{tabular}

Thirteen $\mathrm{T} 1$ progeny plants for each kanamycin sensitive lines analyzed with PCR using F1/gusR and nptIIF/R primers. F1/gusR amplifies $895 \mathrm{bp}$ recombined fragments that presented in the table as excision positive (removal of $n p t I I)$. Positive samples for excision events were analyzed with nptIIF/R primers. NptII negative were scored as complete $n p t I I$ excision. Complete excision efficiency was expressed as a ratio of the number of putative complete marker-free plants to the excision positive plants

free efficiency for kanamycin sensitive lines might be due to various expression pattern of recombinase in embryo (seed) cells at various time points during seed development. It is demonstrated that napin protein was detected in outermost tip of the axis at first, and continued through the axis to the base of the outer cotyledon and further toward its tip during canola seed development (33).

Functionality of different self-excision Cre/loxP systems using tissue-specific promoters investigated in various plants. Luo et al. (2007) used pollen-specfic promoter for cre regulation. They reported 100\% recombination efficiency in tobacco. Germline-specific self-excision Cre/loxP system demonstrated 83100\% marker excision in Arabidopsis (26). Mlynarova et al. (2006) reported $100 \%$ excision rates in tobacco using microspore-specific Cre/loxP self-excision system. Floral-specific Cre/loxP self-excision system demonstrated $37.5 \%$ marker excision rates in rice (25). Li et al. (2007) reported the lower excision efficiency (5-30\%) using embryo-specific self-excision system in soybean. Seed-specific self-excision Cre/loxP system by using cruciferin promoter for cre regulation demonstrated completely marker-free plants in $\mathrm{T} 1$ progenies (27). Hu et al. (2013) reported 10-53\% excision efficiency by using floral-specific promoter and $12-36 \%$ excision efficiency by using seed-specific promoter in rice (38).

Using constitutive promoters for the over expression of transgenes resulted in poor quality plants due to reduced growth and altered development (39). Synthetic inducible promoters provide an efficient and flexible strategy to regulate transgene expression and reduce the complexity of the expression pattern of natural promoters (40).
In our system a synthetic inducible promoter (IPFFDD) drive the gus gene after excision event. This synthetic promoter was constructed by dimerizing $\mathrm{cis}$ acting elements (F) and (D) upstream of the CaMV $35 \mathrm{~S}$ minimal promoter as a phytopathogenic-inducible promoter (41). The F and D elements present in this promoter were selected for their ability of the induction of fungal pathogen elicitors (42) but not by the wound stress $(43,44)$. These two criteria were desirable phenomena for breeding of disease resistant plants (45). Analysis of the induction of the promoters containing $\mathrm{FF}$ and DD against phatogen elicitors showed that these $c i$-acting elements are active in different tissues which might be attacked by the pathogens (41). The functionality and inducibility of FFDD-gus fusion after excision of unwanted DNA is important for this self-excision system (22). The results of histochemical Gus staining assay for $\mathrm{T} 1$ progeny of three kanamycin sensitive lines demonstrated gus expression by induction of FFDD-containing inducible promoter (Figure 5). These data exhibited that 34 bp loxP spacer sequence between IP-FFDD and gus ORF did not interfere in Gus expression. This is similar to the results reported for soybean using embryo-specific cre/loxP self-excision system (35).

In conclusion we constructed a self-excision system based on seed-specific expression of Cre recombinase to eliminate nptII gene and pathogen inducible promoter for regulation of gene of interest in transgenic plants. When selective pressure is needed for efficient selection of transgenic plants, Cre was not expressed during the early tissue culture period, and gene of interest can be induced by pathogen elicitors in T1 transgenic plants after excision. In this self-excision system nptII gene was placed near T-DNA left border. Accordingly, we became certain that primary kanamycin resistant plants contain complete T-DNA. This self-excision system might be an efficient tool for manipulation of crops to produce marker-free transgenic plants. However, it should be noted that the system is applicable only for seed-producing plants.

\section{Acknowledgments}

This research was funded by National Institute of Genetic Engineering and Biotechnology (project No. 407-M). The authors would like to thank Dr L. Kopertekh for kindly providing $\mathrm{pLH}$-cre-gus vector.

\section{References}

1. Halpin C. Gene stacking in transgenic plants-the challenge for $21^{\text {st }}$ century plant biotechnology. Plant Biotechnol J. 
2005;31:141-155. DOI: 10.1111/j.1467-7652.2004.00113.x

2. Miki B, McHugh S. Selectable marker genes in transgenic plants: applications, alternatives and biosafety. J Biotechnol. 2004;107:193-232. DOI: 10.1016/j.biotec.2003.10.011

3. Dale PJ, Clarke B, Fontes EMG. Potential for the environmental impact of transgenic crops. Nat Biotechnol. 2002;20:567574. DOI: $10.1038 /$ nbt0602-567

4. Hare P, Chua N-M. Excision of selectable marker genes from transgenic plants. Nat Biotechnol. 2002;20:575-580. DOI: 10.1038/nbt0602-575

5. Puchta H. Removing selectable marker genes: taking the shortcut. Trends Plant Sci. 2000;5:273-274. DOI: http://dx.doi.org/10.10 16/S1360-1385(00)01684-8

6. Ow DW. The right chemistry for marker gene removal? Nat Biotechnol. 2001;19:115-116.

7. Zhang Y, Li H, Ouyang B, Lu Y, Ye Z. Chemical-induced autoexcision of selectable markers in elite tomato plants transformed with a gene conferring resistance to lepidopteran insects. Biotechnol Lett. 2006;28: 1247-1253. DOI: 10.1007/ s10529-006-9081-z

8. Cotsatifs O, Sallaud C, Breitler JC et al. Transposon mediated generation of T-DNA and marker-free rice plants expressing a Bt endotoxin gene. Mol Breed. 2002;10:165-180.

9. Endo S, Sujita K, Sakai M, Tanaka H, Ebinuma H. Single step transformation for generating marker-free transgenic rice using the ipt-type MAT vector system. Plant J. 2002;30:115122. DOI: $10.1046 / j .1365-313 X .2002 .01272 . x$

10. Luo H, Lyznik LA, Gidoni D, Hodges TK. FLP-mediated recombination for use in hybrid plant production. Plant $J$. 2000;23:423-430. DOI: 10.1046/j.1365-313x.2000.00782.x

11. Ebinuma H, Sugita K, Matsunaga E, Endo K, Yamada S, Komamin A. Systems for the removal of a selection marker and their combination with a positive marker. Plant Cell Rep. 2001;20:383-392. DOI: 10.1007/s002990100344

12. Lyznik LA, Rao KV, Hodges TK. FLP-mediated recombination of frt sites in the maize genome. Nucleic Acids Res. 1996;24:3784-3789.DOI: 10.1093/nar/24.19.3784

13. Hoa TTC, Bong BB, Huq E, Hodges TK. Cre/lox site specific recombination controls the excision of a transgene from the rice genome. Theor Appl Genet. 2002;104:518-525. DOI: 10. 1007/s001220100748

14. Kerbach S, Lorz H, Becker D. Site-specific recombination in Zea mays. Theor Appl Genet. 2005;111:1608-1616. DOI: 10.1007/s00122-005-0092-2

15. Bala A, Roy A,Das A, Chakraborti D, Das S. Development of selectable marker free, insect resistant, transgenic mustard (Brassica juncea) plants using Cre/lox mediated recombination. BMC Biotechnol. 2013;13:88. DOI: 10.1186/1472-6750-13-88

16. Cuellar W, Gaudin A, Solorzano D, Casas A, Nopo L, Chudalayandi P, Medrano M, Kreuze J, Ghislain M. Selfexcision of the antibiotic resistance gene nptII using a heat inducible Cre-loxP system from transgenic potato. Plant Mol Biol. 2006;62:71-82. DOI: 10.1007/s11103-006-9004-3

17. Zhang W, Subbarao S, Addae P, Shen A, Armstrong C, Peschke $\mathrm{V}$, Gilbertson L Cre/lox-mediated marker gene excision in transgenic maize (Zea mays L.) plants. Theor Appl Genet. 2003;107:(11) 57-68.

18. Coppoolse ER, de Vroomen MJ, Roelofs D, Smit J, Van Gennip
F, Hersmus BJM, Nijkamp HJJ, Van Haaren MJJ. Cre recombinase expression can result in phenotypic aberrations in plants. Plant Mol Biol. 2003;51:263-279.

19. Schaart JG, Krens FA, Pelgrom KTB, Mendes O, Rouwendal GJA. Effective production of marker-free transgenic strawberry plants using inducible site-specific recombination and a bi-functional selectable marker gene. Plant Biotechnol J. 2004;2:233-240. DOI: 10.111/j.1467-7652.2004.00067.x

20. Sreekala C, Wu L, Gu Wang D, Tian D. Excision of a selectable marker in transgenic rice (Oryza sativaL.) using a chemically regulated Cre/loxP system. Plant Cell Rep. 2005;24:8694. DOI: 10.1007/s00299-004-0909-5

21. Zuo J, Niu Q-W, Møller SG, Chua N-H. Chemical-regulated site specific DNA excision in transgenic plants. Nat Biotechnol. 2001;19:157-161.

22. Hoff T, Schnorr KM, Mundy J. A recombinase-mediated transcriptional induction system in transgenic plants. Plant Mol Biol. 2001;45:41-49.

23. Wang Y, Chen B, Hu Y, Li J, Lin Z. Inducible excision of selectable marker gene from transgenic plants by the Cre/lox site-specific recombination system. Transgenic Res. 2005;14: 605-614. DOI: 10.1007/s11248-005-0884-9

24. Luo K, Duan H, Zhao D, Zheng X, Deng W, Chen Y, Stewart CN, McAvoy R, Jiang X, Wu Y, He A, Pei Y, Li Y. “GM gene-deletor": fused loxP-FRT recognition sequences dramatically improve the efficiency of FLP or Cre recombinase on transgene excision from pollen and seed of tobacco plants. Plant Biotech nol J. 2007;5:263-274. DOI: 10.1111/j.1467-7652.2006.00237. x

25. Bai X, Wang Q, Chu Ch. Excision of a selective marker in transgenic rice using a novel Cre/loxP system controlled by a floral specific promoter. Transgenic Res. 2008;17:1035-1043. DOI: $10.1007 / \mathrm{s} 11248-008-9182-7$

26. Verweire D, Verleyen K, De Buck S, Claeys M, Angenon G. Marker-free transgenic plants through genetically programmed auto-excision. Plant Physiol. 2007;145:1220-1231. DOI: http://dx.doi.org/10.1104/pp.107.106526

27. Moravcikova J, Vaculkova E, Bauer M, Libantova J. Feasibility of the seed specific cruciferin $\mathrm{C}$ promoter in the self excision Cre/loxP strategy focused on generation of marker-free transgenic plants. Theor Appl Genet. 2008;117: 1325-1334. DOI: 10.1007/s00122-008-0866-4

28. Sambrook J, Fritsch EF, Maniatis T. Molecular cloning: a laboratory manual, $2^{\text {nd }}$ ed. Cold Spring Harbor Laboratory Press, Cold Spring Harbor; 2013.

29. Sprenger-Haussels M, Weisshaar B. Transactivation properties of parsley proline-rich bZIP transcription factors. Plant J. 2000; 22:1-10. DOI: 10.1046/j.1365-313x.2000.00687.x

30. Kopertekh L, Broer I, Schiemann. Developmentally regulated site-specific marker gene excision in transgenic B. napus plants. Plant Cell Rep. 2009;28:1075-1083. DOI: 10.1007/s 00299-009-0711-5

31. Horsch RB, Fry JE, Hoffman NL, Wallroth M, Eichholtz D, RogersSG, Fraley RT. A simple and general method for transferring genes into plants. Science 1985;227:1229-1231.

32. Jefferson RA, Kavanagh TA, Bevan MW. GUS fusion: $\beta$-glucuronidase as a sensitive and versatile gene fusion marker in higher plants. EMBO J. 1987;6:3901-3907.

33. Hoglund A, Rodin J, Larsson E, Rask L. Distribution of napin 
and cruciferin in developing rape seed embryos. Plant Physiol. 1992;98:509-515. DOI: http://dx.doi.org/10.1104/ pp.98.2.506

34. Stalberg K, Ellerstrom M, Josefsson L-G, Rask L. Deletion analysis of a $2 \mathrm{~S}$ seed storage protein promoter of Brassica napus in transgenic tobacco. Plant Mol Biol. 1993;23: 671683. DOI: 10.1007/BF00021523

35. Li Z, Xing A, Moon BP, Burgoyne SA, Guida AD, Liang H, Lee C, Caster CS, Barton JE, Klein TM, Falko SC. A Cre/loxP mediated cell autonomous gene excision system to produce marker gene free transgenic soybean plants. Plant Mol Biol. 2007; 65: 329-341. DOI: 10.1007/s11103-007-9223-2

36. Mlynárová L, Conner AJ, Nap JP. Directed microspore-specific recombination of transgenic alleles to prevent pollenmediated transmission of transgenes. Plant Biotechnol J. 2006;4:445-452. DOI: 10.1111/j.1467-7652.2006.00194.x

37. Moon HS, Li Y, Stewart CN Jr. Keeping the genie in the bottle: transgene bio containment by excision in pollen. Trends Biotechnol. 2010;28:3-8. DOI: http://dx.doi.org/10.1016/j. tibtech.2009.09.008

38. Hu Z, Ding X, Hu S, Sun Y, Xia L. Tissue-specifically regulated site-specific excision of selectable marker genes in bivalent insecticidal, genetically-modified rice. Biotechnol Lett 2013;35:2177-2183. DOI: 10.1007/s10529-013-1310-7

39. Gurr SJ, Rushton PJ . Engineering plants with increased disease resistance: what are we going to express. Trends Biotechnol. 2005;23:275-282. DOI: http://dx.doi.org/10.1016/j.tibtech.
2005.04.007

40. Venter M. Synthetic promoters: genetic control through cis engineering. Trends Plant Sci. 2007;12:118-124. DOI: http://dx.doi.org/10.1016/j.tplants.2007.01.002

41. Shokouhifar F, Zamani M.R, Motallebi M, Mousavi A, Malboobi M.A. Construction and functional analysis of pathogen-inducible synthetic promoters in Brassica napus. Biologia Plantarum. 2011;55:689-695. DOI: 10.1007/s10535 -011-0169-5

42. Heise A, Lippok B, Kirsch C, Hahlbrock K. Two immediateearly pathogen-responsive members of the AtCMPG gene family in Arabidopsis thaliana and the Wbox-containing elicitors-response element of AtCMPG1. Proc Nat Acad Sci. 2002; 99:9046-9054. DOI: 10.1073/pnas.132277699

43. Kirsch C, Logeman E, Lippok B, Schmelzer E, Hahlbrock K. A highly specific pathogen-responsive promoter element from the immediate-early activated CMPG1 gene in Petroselinum crispum. Plant J. 2001;26:217-227. DOI: 10.1046/j.1365-313 x.2001.011015.x

44. Nurnberger T, Brunner F. Innate immunity in plants and animals: emerging parallels between the recognition of general elicitors and pathogen-associated molecular patterns. Curr Opin Plant Biology. 2002;5:318-324. DOI: 10.1016/S13695266(02)00265-0

45. Hammond-Kosack KE, Parker JE. Deciphering plant-pathogen communication: Fresh perspectives for molecular resistance breeding. Curr Opin Biotechnol. 2003;14:177-193. DOI: 10.1016/S0958-1669(03)00035-1 